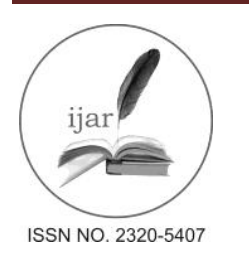

Journal homepage: http://www.journalijar.com
Journal DOI: 10.21474/IJAR01

INTERNATIONAL JOURNAL

OF ADVANCED RESEARCH

RESEARCH ARTICLE

\title{
UNDERSTANDING AND PRACTICALITY IN IMPLEMENTATION OF DISCRIMINATION AND SOCIAL EXCLUSION: A STUDY OF RELIGIOUS MINORITY P.G. YOUTH FROM MUMBAI CITY.
}

\author{
Dr. Tajoddin Ladaf ${ }^{1}$, Dr. Prashant Vaidande ${ }^{2}$. \\ 1. Assist. Prof. in Economics, SSA's Arts and Commerce College, Solapur, \\ 2. Consultant, Mumbai.
}

\section{Manuscript Info}

Manuscript History:

Received: 15 May 2016

Final Accepted: 29 June 2016

Published Online: July 2016

Key words:

Discrimination, Exclusion,

Employment generative education,

Minority Youth development.

*Corresponding Author

Dr. Tajoddin Ladaf.

\begin{abstract}
India the Nation, is very well known to the whole world with its peculiarities, like its social stratification and caste category including religious uniqueness in the world. The article also grills the different forms of social contexts, which leads to inclusion and exclusion practically on the basis of empirical evidence. Indian constitution has given all rights to everyone without any discrimination. But in practically it is still a myth for religious minority groups in Indian. The social stratification is strongly implemented in the rural part of the India (country) with the reference to available literature and practical experience, but it is also a myth. Though the Dr. B.R.Ambedkar said to leave the village and move to the urban city to break this Social stratification cycle. After accepting constitution and laws, still (backward class) specially converted Muslim, Christian, Buddhists (New-Buddhist) are socially discriminated, exclude, communities for getting socially exclusive treatment in the city on the various ground like education, employment, housing status, economic condition, water, cleanliness, surrounding of housing area etc. As data was collected from 250 P.G. youth of Mumbai, it reveals the adverse situation opposite to Constitutional rights. It is not only on the basis of theoretical, philosophical but evidence-based results. This provoked the exclusive condition of Indian Minority Youth and their family. This paper focuses on selected results. The major concern of this paper is to show how Minority people are underdeveloped excluded in an urban area on various grounds, with the consequence and recommendations from the social work perspective here are presented as same.
\end{abstract}

Copy.Right. IJAR 2016. All rights reserved.

\section{Introduction:-}

It is like a universal truth, which not only applicable to India but for whole world. There was, is and will be a very close association between social exclusion (purposeful, unfavourable exclusion with differential treatment (Discrimination), deprivation and poverty among socially excluded groups (as per social stratification). The unfair exclusion with differential treatment results in low access and participation of marginalised and socially excluded population groups, which ultimately causes high poverty and low human development among the excluded minority groups.

(Ministry of Minority Affairs Govt. of India, 2007) The Universal Declaration of Human Rights 1948 and its two International Covenants of 1966 declare that "all human beings are equal in dignity and rights" and prohibit all kinds of discrimination - racial, religious etc. The UN Declaration against all Forms of Religious Discrimination and Intolerance 1981 outlaws all kinds of religion-based discrimination. The UN Declaration on the Rights of Minorities 1992 enjoins the States to protect the existence and identity of minorities within their respective territories and encourage conditions for promotion of that identity; ensure that persons belonging to minorities fully and effectively 
exercise human rights and fundamental freedoms with full equality and without any discrimination; create favourable conditions to enable minorities to express their characteristics and develop their culture, language, religion, traditions and customs; plan and implement national policy and programmes with due regard to the legitimate interests of minorities; etc.

\section{Meaning of Minority:-}

According to Encyclopaedia Britannia, 'minorities', means "groups held together by ties of common descent, language or religious faith and felling different in these respects from majority of the inhabitants of given political entity". The Bench of SC opined that the word 'minority' literally means a non-dominant group (Bhuimali, 2008).

The Oxford Dictionary defines 'Minority' as a smaller number or part; a number or part representing less than half of the whole; a relatively small group of people, differing from others in race, religion, language or political persuasion".

"Minority are particular racial, cultural, religious or nation al groups, who, although living among other groups, do not fully share in the culture that they are a part of" (Fried, 1983).

Sociologically minority means a group that does not constitute a politically dominant voting majority of the total population in a given society. In socio-economics, the term "minority" typically refers to a socially subordination ethnic group (in terms of language, nationality, culture and religion) (Garg, 2011).

A special Sub-Committee on the Protection of Minority Rights appointed by the United Nations Human Rights Commission in 1946 defined the 'minority' as those "non-dominant groups in a population which possess a wish to preserve stable ethnic, religious and linguistic traditions or characteristics markedly different from those of the rest of population."

As per Dr. B.R.Ambedkar Article 23 (presently Article 30), "The term 'minority' was used not in the technical sense of the word minority as we have been accustomed to use it for purpose of certain political safeguards such as representation in the legislature, representation in the services and so on'.

As per the report of NCRLM (Ministry of Minority Affairs Govt. of India, 2007) the Constitution of India uses the word 'minority' or its plural form in some Articles -29 to 30 and 350A to $350 \mathrm{~B}$ - but does not define it anywhere. Article 29 has the word "minorities" in its marginal heading but speaks of "any sections of citizens.... having a distinct language, script or culture." This may be a whole community generally seen as a minority or a group within a majority community. Article 30 speaks specifically of two categories of minorities - religious and linguistic. The remaining two Articles $-350 \mathrm{~A}$ and 350B relate to linguistic minorities only.

In A.M. Patrani Vs. Ke Shavan 1965 case SC was held that the word minority is not defined in the constitution and in the absence of special definition, it must be held that any community, religion or linguistic, which is numerically less than $50 \%$ of the population of the state is entitled to the right under the Article 30 (Bhuimali, 2008).

In common parlance, the expression "minority" means a group comprising less than half of the population and differing from others, especially the predominant section, in race, religion, traditions and culture, language, etc.

Religious Minorities in India:- As per the census 2011 India, regarding religious minorities at the national level in India, India now has 966.3 million Hindus, who make up 79.8 per cent of its population, and 172.2 million Muslims, who make up 14.23 per cent. Among the other minorities, Christians make up 2.3 per cent of the population and Sikhs 1.72 per cent. The distribution of data is of the total population by six major religious communities - Hindu, Muslim, Christian, Sikh, Buddhist and Jain — besides "Other religions and persuasions" and "Religion not stated".

\section{Who are these minorities?}

As per the above mentioned several definition and meanings one can say that these particular groups are the minority groups on the basis of certain criterion. But in the context of India we need to pay special attention on these minority groups. Who are these minority people, as we all know with the help of historical background that INDIA so call (BHARAT) the continent was non-religious/ all the existed religions are migrated from other continent to INDIA. The original Indians were non-religious and now whatever current religious minority peoples group are 
majority converted original Indians. The conversion of these groups happens with many reasons; it started from Hindu religion to all other minority religious groups. So all the religious minorities majority population is converted (Back ward people like- SC, ST, OBC and all socially exclude castes by Hindu religion). By their norms, culture and patterns of traditions one can easily recognised.

Table No.1:- National level Religious Minority in India Census Data 2011

\begin{tabular}{|l|c|c|c|c|}
\hline Religion & Percentage & Estimated in Crores & Total & State Majority \\
\hline All Religion & 100.00 & 121 & $1,210,854,977$ & 35 \\
\hline Hindu & 79.80 & 96.62 & $966,257,353$ & 28 \\
\hline Muslim & 14.23 & 17.22 & $172,245,158$ & 2 \\
\hline Christian & 2.30 & 2.78 & $27,819,588$ & 1 \\
\hline Sikh & 1.72 & 2.08 & $20,833,116$ & - \\
\hline Buddhist & 0.70 & 84.43 Lakhs & $8,442,972$ & - \\
\hline Jain & 0.37 & 44.52 Lakhs & $4,451,753$ & - \\
\hline Other Religion & 0.66 & 79.38 Lakhs & $7,937,734$ & - \\
\hline Not Stated & 0.24 & 28.67 Lakhs & $2,867,303$ & \\
\hline \multicolumn{2}{l}{ Sources: http://www.census2011.co.in/religion.php } \\
\hline
\end{tabular}

Table No. 1 shows the national level religious minority groups. Muslims are the largest minority. Other minorities are much smaller in size. Next to the Muslims are the Christians (2.30 per cent) and Sikhs (1.72 per cent); while all the other religious groups are still smaller.

The Constitution also contains provisions which guarantee certain minimum rights for all its citizens, religious freedom by Article 25, and Article 15 explicitly prohibits discrimination based on religion and Article 51 imposes a positive duty on the citizens to promote harmony and the spirit of common brotherhood among all the people of India. It also specifies duties which the State should discharge for social and economic development of backward classes, especially religious minority and Scheduled Castes, Scheduled Tribes. The rights of the citizens are guaranteed under the Chapter on Fundamental Rights contained in the Constitution.

Article 46 under the Directive Principles of State Policy provides that "The State shall promote with special care, the educational and economic interest of weaker sections of the people and in particular of SC, ST and religious minority shall protect them from social injustice and all forms of exploitation". The Constitution provides various safeguards to implement objectives preserved in the preamble to the Constitution. These safeguards include social, economic, educational, cultural, political and service.

Educational exclusion: Article 15(4) empowers the State to make special provisions for advancement of any socially and economically backward classes, like Scheduled Castes/ Scheduled Tribes and including religous minority. Indian society (So called Higher) has made prestigious categories in education faculty, and on the basis of that exclusive discrimination, unseen and under- cloth balme game cointinues from independenc. There is a lack of political will regarding the development of SC, ST and religious minority. There is increasing populism to fetch the votes of (under-developed) SC, ST and religious minorities and very few sincere efforts for their development. Exclusion of education to underdeveloped community youth is reality but they are not fully aware of it. First exclusion step is on the basis of employment generative education and prestigious education. Second exclusion step is for underdeveloped youth is that they should not reach to any one of above educational faculty, for that various other schemes were invented, so that they will feel that govt. is doing some thing for them, as per indian constitution. Third exclusion step is like increasing of admission fees, demanding bribes for conformation of admission, limiting the govt. seats, these all poison things consciously doing by higher community. so that underdeveloped youth should not enter in the open competition with open youth. Some of the empirical evidences are brought forward to prove this reality through table No.6.

Exclusion of shelter inhibition: Mumbai's citizens represent nearly all the religions practiced in India and many from abroad. The urban centres offering diverse employment opportunities and means of livelihood are the main centres of attraction for migration, despite the fact that physical infrastructure i.e. housing, drinking water supply and drainage are inadequate (Registrar General and Census Commissioner, India, 2001a). 
Slums are linked with the British rule in India. A majority of the rural migrants, not only displaced in the process of colonial development, but migrated to large cities for seeking employment, to get total freedom from rural old existed social stratification system.

Basically all these slums were get developed on peripheral and marginal lands on the outskirts of city, hills, slopes and low lying areas, and land which has little use to the owner in near future. They also developed on the land left unused by public bodies like Railway, Municipal Corporation, Port Trust, TATA Power Supply Co, etc. (Nangia and Gupta, 1993).

Some of the worst slums in the world can be found in Indian cities. Due to the lack of infrastructure and planning in the cities, they are helpless of accommodating the increasing flow of migrants from the rural areas.(Desai and Pillai, 1970).

Dharavi, Asia's second largest slum (if Karachi's Orangi Town is counted as a single slum is located in central Mumbai and houses between 800,000 to one million people, in 2.39 square kilometres, making it one of the most densely populated areas on Earth with a population density of at least 334,728 persons per square kilometre (http://www.Dharavislums). Dharavi the densely populated place which is the outskirts of Main Mumbai City or the end boundry of Mumbai city, secondly various other major slums are situated outskirt of Suburban Mumbai like Mankhurd-Govandi which is the end boundry of MCGM, Borivali-Dahisar Slums are the end boundry of MCGM (Sub-urban Mumbai) for west site, are the coastal sewage low lying area, city garbage- west collection and disposal centre of MCGM, where all these listed slums are developed by all excluded people specially SC,ST and Religious minority from not only in India but from Maharashtra as well. Some of the empirical evidences are brought forward to prove this reality through table No.5.

The majority of the slum population is concentrated in core areas of the city because they want to live nearer to their working places and contribute significantly to the economic activity of the city. (Mundu \& Bhagat, 2008) Most of places where slum dwellers live are unhygienic to the lives. This is a big problem in Mumbai which warrants immediate attention.

Minorities in Mumbai:- Table No.2 shows the status of religion wise minority in Mumbai. Hinduism is majority religion in Mumbai city with $60.73 \%$ followers. Islam is second most popular religion in city of Mumbai with approximately $25.06 \%$ following it. In Mumbai city, Christianity is followed by $2.74 \%$, Jainism by $5.38 \%$, Sikhism by $0.44 \%$ and Buddhism by $4.35 \%$. Around $1.01 \%$ stated 'Other Religion'; approximately $0.29 \%$ stated 'No Particular Religion'.

Table No.2:- Religion wise minority in Mumbai.

\begin{tabular}{|l|l|c|c|}
\hline Sr.No & Religion & Mumbai City & Mumbai Suburban \\
\hline 1 & Hindu & $60.73 \%$ & $67.73 \%$ \\
\hline 2 & Muslims & $25.06 \%$ & $19.19 \%$ \\
\hline 3 & Buddhist & $4.35 \%$ & $3.45 \%$ \\
\hline 4 & Jain & $5.38 \%$ & $0.51 \%$ \\
\hline 5 & Christian & $2.74 \%$ & $5.02 \%$ \\
\hline 6 & Sikh & $0.44 \%$ & $3.67 \%$ \\
\hline 7 & Other Religion & $1.01 \%$ & $0.20 \%$ \\
\hline 8 & Not Stated & $0.29 \%$ & $0.24 \%$ \\
\hline \multicolumn{2}{|l|}{ Sources: http://www.census2011.co.in/data/religion/state/27-maharashtra.html } \\
\hline
\end{tabular}

Hinduism is majority religion in Mumbai Suburban with $67.73 \%$ followers. Islam is second most popular religion in Suburban Mumbai with approximately $19.19 \%$ following it. Christianity is followed by $5.02 \%$, Jainism by 0.51 $\%$, Sikhism by $3.67 \%$ and Buddhism by $3.45 \%$. Around $0.20 \%$ stated 'Other Religion'; approximately $0.24 \%$ stated 'No Particular Religion'. 
The problem of slums has been faced at some point of time by almost all the major cities throughout the developing world. One-third of third city population are slum dwellers. According to the last 2001 and current census of India 2011, Mumbai is a place where more than half of its inhabitants (54.4\%) live in the slum areas. Mumbai slum dwellers form the largest group of people among the metropolitan areas of India.

According to the 2011 census, Mumbai City district has a population of 3,145,966. Roughly equal to the population of Mongolia or the US state of Iowa. Population density is 20,038 inhabitants per square kilometre (51,900/sq mi). Of this population, over 50 per cent are slum and pavement dwellers, occupying, by many calculations, a mere 8 per cent of Mumbai's land area. Thus, Mumbai is a city that is often represented as a study in contrasts where well-off high-rise apartments side poor infrastructural-deprived slum settlements (http://en.wikipedia.org/wiki/Mumbai_City_district\#cite_note-districtcensus-0).

In the Indian era of inclusion to excluded community in the main stream of population various measures were initiated. On paper the design of inclusion was very effective, result oriented, but in practically it was not. The designer of measure and implementer was totally biased with these excluded communities. In other words with example of Mumbai Region which is a part of City and Sub-urban area. City area is planned and developed as per dominant peoples demand and need. While fulfilling their need administrator again developed another area called sub-urban area.

Table No.3:- Discrimination and Exclusion on the basis of living area.

\begin{tabular}{|l|l|l|l|l|l|l|}
\hline Name of the District & Age groups & Total (All) & Total (SC) & Total (ST) & SC\% & ST\% \\
\hline Greater Mumbai (M.cop) & All ages & 11978450 & 585038 & 91120 & 4.88 & 0.76 \\
\hline Mumbai (City) & All ages & 3338031 & 183469 & 20666 & 5.49 & 0.61 \\
\hline Mumbai (suburban) & All ages & 8640419 & 401569 & 70454 & 4.64 & 0.81 \\
\hline Census of India 2001 & All ages & 12442373 & 803236 & 129653 & & \\
\hline Greater Mumbai (M.cop) & All ages & 3085411 & 219934 & 25093 & 7.13 & 0.81 \\
\hline Mumbai (City) & All ages & 9356962 & 583302 & 104560 & 6.23 & 1.12 \\
\hline Mumbai (suburban) & \multicolumn{5}{|l|}{} \\
\hline Census of India 2011
\end{tabular}

Source: Directorate of census operation, Maharashtra-Mumbai. Census of India 2001. Analytical table of Greater Mumbai Municipal Corporation.

The above table No. 3 shows the facts and figure about underdeveloped community and their presence in the so called inclusive Metropolitan city, financial capital of India which is called as MUMBAI. Exclusion on the presence of living in the city shows that in the Greater Mumbai developed community which is (94.35\%) ,Mumbai city $(93.88 \%)$ and Mumbai sub-urban (94.53\%) compare to underdeveloped community developed community people will find in more number in developed area then undeveloped area called sub-urban area which is still waiting to get develop like Mumbai city. It is also a kind of unseen, unobservable, knowingly but showing unknowing exclusion or denial of basic needs like shelter at the heart of the city to undeveloped community people.

\section{Review of literature:-}

(Alam, 2009) The power relation thesis maintians that the increasing size of minority groups leads to a competition for scarce resources. As minoiryt groups are genrally poor in human and other forms of captial, there are significant power differnces bteween them and the majority group. In such a situation, the stronger group (the majority) is able to deny the weaker one (the minority) of crucial resources, specailly those needed for building human capital. The condition is not improved by the state because poor is in the hands of wealther groups, which are unwilling to redistribute resources to others (Mitra 1992; and Chakravorty 2006).

(Garg, 2011) According to Peter Robert Saunnders, in modern Wstern societies, stratification depends on social and economic classes comprising three main layres: upper class, middle class and lower class related, inn part, to occupation. The term stratification derives from the geological concept of strata, or rock layers created by natural processes.

A numbeer of studies have been counducted to draw the focuse on relationship between the relative size of minority populations and the differnece in socio-economic in equalities that existed inn majority and minority groups 
(Blalock1956; Glenn1964; Brown and Fuguitt 1972; Frisbie and Neidert 1977; Tienda and Lii 1987). It is the proven throuth that the larger the size of the minority populations, the greater the socio-economic inequalty between minority and majority gropus. In the context of India Betancourt and Gleason (2000) obsreved an inverse relationship between the relative size of Muslim and Scheduled Caste populations and the allocation of public goods and services in rural area. It is also very closly applicable to urban areas as well. The Sachar Committee Report (SCR) 2006 noted that districts with a relatively large minority population (Muslim) were marked by lower level of social development compared to ones having a lower proportion of Muslim (Alam, 2009).

According to (Nair, Vemuri, \& Ram, 1989) the present Educational institution system does not help the student to progress. Their mind is crammed with facts before it knows how to think. Even when these alarming obstacles are overcome and a certificate obtained, the youth cannot yet have a sigh of relief. The problems have not ended, but only begun. In spite of spending so much money and valuable time, the youth cannot stand on their own feet and earn their bread. They are not sufficient enough in any profession so as to adopt it confidently. The job opportunities are less. Owing to widespread corruption and favouritism one finds it very difficult to secure the right job. Even when success smiles upon the young man, many a times the earning is not enough to make both ends meet. Education being the panacea (universal remedy) for all evils, there is also a great urgency to implement the right type of reforms in the present system by making education up to the pre degree level employment oriented.

(Internatonal Institute of Population Sciences (IIPS), 2008)Findings also suggest substantial levels of unemployment among youth $14 \%$ among young men and $16 \%$ among young women. Unemployment was particularly high among the educated young men and women who had completed Class 12 reported considerably higher rates of unemployment than those who had completed fewer years of schooling. Youth were clearly interested in acquiring skills that would enable employment generation; over half of young men and two-thirds of young women reported interest in vocational skills training. However, far fewer just $21 \%$ of young men and $25 \%$ of young women had attended at least one vocational training programme. They all belongs to minority and socially excluded gropus. The rates were particularly low among several sub-groups of youth like young women, married youth, rural youth, those belonging to poor households, Religious minority Youth and those belonging to scheduled castes and tribes. These all are the practical evidences after the safeguards introduced by Indian constitution.

As per (NHRC,2004) report the second part of this strategy relating to compensatory discrimination is reflected in making provisions for reservation of posts in public services through recruitment and promotion, reservation of seats in admission to Educational and Professional Institutions, including relaxation of eligibility qualifications. This was done with a view to ensuring that members of these communities have their share in positions of power and decision making as also access to opportunities for higher education. It was felt that in open competition they may not be able to obtain their legitimate share because of their accumulated disabilities over centuries. These provisions had the intended objective of bridging the vast gap that existed between these groups and the rest of the society in these areas.

Social scientists and policy makers have now begun to recognise the linkages between social exclusion (unfavourable exclusion or unfavourable inclusion, or inclusion/access with differential treatment) and high deprivation and poverty of social groups which have suffered from social exclusion and discrimination of various types through the ages. It is also recognised that unfair exclusion or unfair inclusion with differential treatment results in low access to Income earning assets, employment, as well as social needs like education, health services, food and housing. It also leads to unequal access to civil, religious and cultural rights, political rights and unequal participation in governance which ultimately result in high poverty and low human development among the excluded groups (Thorat \& Sabharwal, 2010).

The Yashpal Committee Report (Government of India, 2009) has emphasis on the higher education " as a means to overcome caste and class hierarchy, patriarchy and other cultural prejudices, and also as a source of new knowledge and skills, a space for creativity and innovations" (Powar, 2012).

\section{Objective:-}

1. To draw a focus on emerging problems pertaining to youth from Religious Minority section.

2. To determine the major causes of declining the vulnerability of excluded religious minority youth.

3. To suggest a plan Programs for meeting and resolving needs of religious minority youth. 


\section{Methodology:-}

This study has used primary data collected from the 250 Youth of selected P.G. colleges in Mumbai. Explanatory research design, has been used which helps to explain the more details about the developmental issues of youth from Mumbai with their background information. The sampling design adopted for the study is three stages stratified sampling method. For selecting the respondent Accidental sampling selection method were applied. Non-Probability Sampling technique for selection of respondents were used. Multistage Stratified accidental sampling method used for data collection for this study. Self administered questionnaire (SAQ), researcher has used for Collection of data in this study. Quantitative approach has used for data collection. Bi-variate analyses have been used for analyzing these data, with the intention to show the relationship between the Socio-economic indicators and selection of faculty education by P.G Youth in Mumbai.

\section{Results and discussion:-}

The empirical evidence collected from P.G. youth of Mumbai City, as described by them in discussions and interviews.

\section{Graph No 1 Respondent's Religion.}

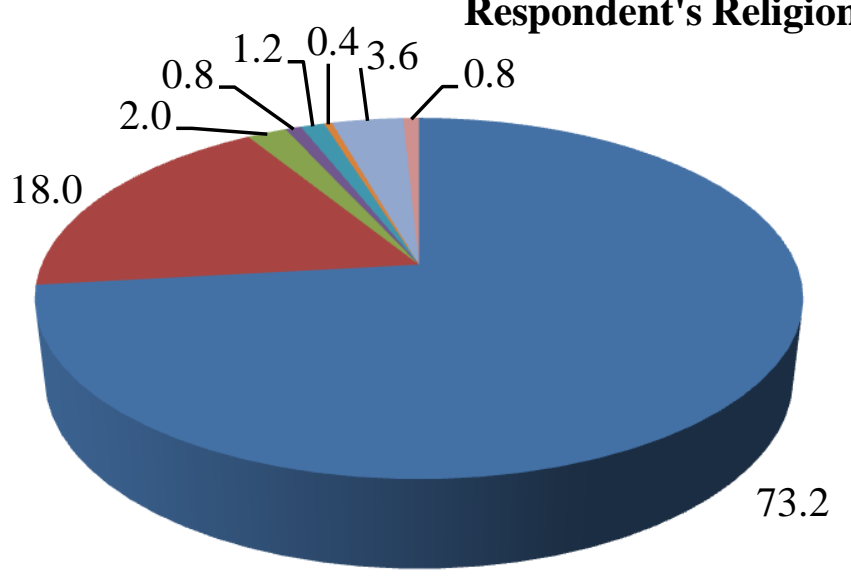

Hindu
Muslim
Christian
Shikh
Jain
Parshi
Buddhist/New Buddhist
No Response

Graph No.1 reveals that Mumbai is India in miniature and is unlike other Indian cities. It has allowed people to make it their home without any discrimination on the basis of religion, cast, class, race, colour etc.73.2 per cent of the respondents were Hindus, 18.0 per cent Muslims, 3.6 per cent were Buddhist/Neo- Buddhist and 5per cent was made up of Christians, Jains, Sikhs, Parsis. It is obvious that the national values are of unity and national integrity is reflected in Mumbai's demographics.

Table No.4:- Caste distribution with non-minority and religious minority groups.

\begin{tabular}{|l|c|c|c|c|}
\hline Caste & Non-minority (Hindu) & Religious minority & NR & Total \\
\hline SC & $17(7.1)$ & $9(3.8)$ & $0(.0)$ & $26(10.9)$ \\
\hline ST & $4(1.7)$ & $0(.0)$ & $0(.0)$ & $4(1.7)$ \\
\hline OBC & $23(9.6)$ & $1.4)$ & $0(.0)$ & $24(10.0)$ \\
\hline OPEN & $75(31.4)$ & $51(21.3)$ & $0(.0)$ & $126(52.7)$ \\
\hline NR & $63(25.2)$ & $5(2.0)$ & $2(.8)$ & $70(28.0)$ \\
\hline Total & $\mathbf{1 8 2 ( 7 2 . 8 )}$ & $\mathbf{6 6}(\mathbf{2 6 . 4})$ & $\mathbf{2 ( . 8 )}$ & $\mathbf{2 5 0}(\mathbf{1 0 0 . 0})$ \\
\hline
\end{tabular}

The Table No.4 show Over 50 per cent students belonged to the Open (general Caste) category, among them 31.4 per cent were Non-minority and 21 per cent found to be from religious minority groups. 11 per cent were SCs among them 7.1 per cent were non-minority and 3.8 per cent found from religious minority groups. 10 per cent from the $\mathrm{OBC}$ category among them 9.6 per cent were non-minority and very less .4 per cent found religious minority. STs formed the smallest group with just 1.7 per cent and 28.0 per cent did not declare their caste because of the sensitive nature of the issue. 
Table No.5:- Discrimination and Exclusion of Minorities on the basis of living condition.

\begin{tabular}{|l|c|c|c|c|}
\hline Present Address Area & Non-Minority (Hindu) & All Religious Minority & N.R & Total \\
\hline Urban & $71(28.4)$ & $28(11.2)$ & $1(.4)$ & $100(40.0)$ \\
\hline Sub-Urban & $106(42.4)$ & $34(13.6)$ & $1(.4)$ & $141(56.4)$ \\
\hline Semi-urban & $1(.4)$ & $2(.8)$ & $0(.0)$ & $3(1.2)$ \\
\hline N.R & $4(1.6)$ & $2(.8)$ & $300)$ & $6(2.4)$ \\
\hline Type of House & \multicolumn{5}{|l}{} \\
\hline Pakka & $83(33.2)$ & $26(10.4)$ & $1(.4)$ & $110(44.0)$ \\
\hline Planed colony & $68(27.2)$ & $32(12.8)$ & $0(.0)$ & $100(40.0)$ \\
\hline University Hostel & $10(4.0)$ & $2(.8)$ & $1(.4)$ & $13(5.2)$ \\
\hline Slum & $17(6.8)$ & $6(2.4)$ & $0(.0)$ & $23(9.2)$ \\
\hline N.R & $4(1.6)$ & $0(.0)$ & $0(.0)$ & $4(1.6)$ \\
\hline Total & $\mathbf{1 8 2 ( 7 2 . 8 )}$ & $\mathbf{6 6 ( 2 6 . 4 )}$ & $\mathbf{2 ( . 8 )}$ & $\mathbf{2 5 0}(\mathbf{1 0 0 . 0})$ \\
\hline
\end{tabular}

Table No.5 revels the facts about living conditions of religious minority (un-develop) community. Exclusion on the basis of living area, compare to city sub-urban area is not that much developed and where almost over 50 per cent population is accumulated, means we can say that it is in development process or undeveloped area. On the various level like basic amenities, facilities, local transport, educational facilities, Hospital and medical facilities. For all these things which are needed for quality life, all suburban citizens have to be depend on the city. Not only that but it is also far away for them to reach there, with cost, time, energy etc. and Hindu and religious minority backward groups are lacking in all these things, they don't have that much money to reach because the place where they are staying in the sub-urban area is like remote area for Mumbai city. Majority SC (included religious minority) stays in the economic class of BPL. The reality which is existed from many years for socially backward class people, after migrating to urban area still they are staying in that status which was in the rural area.

House conditions area or location of house/ living conditions has its own importance and impact on over all development of youth. The data of present study shows that majority 44 per cent among them 10.4 per cent of all religious minority youth respondents reported that they are staying in Pakka house, this Pakka house belongs to a major part of Mumbai slum which is made up of concrete material and compare to hut good in condition within slum. 40 per cent among them 12.8 per cent of all religious minority youth were reported that they are staying in planned colony, means well build planned buildings colony. 9.2 per cent among them 2.4 per cent of all religious minority youth were reproted they are staying in Slums. Whereas 4 per cent youth did not reported their housing condition.

Table No. 6:- Discrimination on the basis of family Income and preferance to education faculty.

\begin{tabular}{|l|l|l|l|l|}
\hline Type of family Income & Non-Minority (Hindu) & All Religious Minority & N.R & Total \\
\hline Lower Class (below BPL) & $55(22.0)$ & $18(7.2)$ & $0(.0)$ & $73(29.2)$ \\
\hline Middle Lower (BPL) & $43(17.2)$ & $19(7.6)$ & $1(.4)$ & $63(25.2)$ \\
\hline Middle Class & $27(10.8)$ & $15(6.0)$ & $1(.4)$ & $43(17.2)$ \\
\hline Upper Middle Class & $18(7.2)$ & $5(2.0)$ & $0(.0)$ & $23(9.2)$ \\
\hline High Class (Rich) & $25(10.0)$ & $7(2.8)$ & $0(.0)$ & $32(12.8)$ \\
\hline NR & $14(5.6)$ & $2(.8)$ & $0(.0)$ & $16(6.4)$ \\
\hline Preference to Educational Faculty & $12(4.8)$ & $0(.0)$ & $50(20)$ \\
\hline Art's & $38(15.2)$ & $12(4.8)$ & $1(.4)$ & $50(20)$ \\
\hline Commerce & $37(14.8)$ & $15(6.0)$ & $0(.0)$ & $50(20)$ \\
\hline Science & $35(14.0)$ & $14(5.6)$ & $1(.4)$ & $50(20)$ \\
\hline Technical & $35(14.0)$ & $13(5.2)$ & $0(.0)$ & $50(20)$ \\
\hline Professional & $37(14.8)$ & $\mathbf{6 6}(\mathbf{2 6 . 4})$ & $\mathbf{2 ( . 8 )}$ & $\mathbf{2 5 0}(\mathbf{1 0 0 . 0})$ \\
\hline Total & $\mathbf{1 8 2 ( 7 2 . 8 )}$ &
\end{tabular}

Tabel No. 6 Shows Non-Minority and all religious minority parent's education, family Inncome and preference of faculty education. History also revels the fact that those who have educated parental background with economic support it is advantage for them to select or go for employment generative or Prestigious education site. Basically educated parent's takes decision about their children's education. Data shows the Parents Education and family 
Income wise preference to selection of faculty education. Majority 29.2 per cent among them 15.8 percent youth were reported that their Family income comes under lower class and 25.2 per cent ammong them 7.6 per cent reported Middel Lower category (below and under BPL) how are religious minority. Form that most 4.8 percent youth respondents were given preference to arts and commerce faculty respectively. Whereas they are not willing to opt / go for professional education as the fees is not affordable for them. Around 6 percent of the respondents from minority and Middel calss income group opted science and only 2 and 2.8 percent of respondets from upper Middel Calss and High Class Income were found in the minoirty group selected engineering and Professional education faculty which is negligible. The situation of middle class youth student shows that majority of them have given preference to professional education \& engineering. However very few of them found taken admission to arts, science \& commerce faculty. Whereas 6.4 percent of respondents do not reported their family income.

\section{Conclusion:-}

Indian society due to its social stratification and caste category is unique in the world. On the basis of that Indian society have made prestigious categories in education faculty. The categories were ranked like prestigious, nonprestigious, higher status - Lower Status, High class people's education- Lower class people's education, High income generative education-Low income generative education

Basically Open (Social Class) category population the all religious minority groups comes under this category. Among them with better economic background always tries to maintained their status, and for that they always gives preference to engineering faculty which is all together prestigious in all manners, in income and social status as well.

Whereas most of the religious minoiryt groups have the other subcategories like SC,ST and other backword, due to constitutional rights slowly they are going for Science \& engineering faculty, then Professional education. At the end if they did not get chance to employment generative faculty then they go for arts and commerce faculty respectively.

As it is psychologically or we can say that due to social pressure for maintaining their social status/position in the Housing area/community, society parents send their children for studying in the high prestigious faculty of study.

On the basis of housing condition those who are staying in Building, means in the socially, economically developed area where all basic amenities provided and they are enjoying it fully.

Still cities major population is conncentrated specially youth from excluded (All religious minority and SC,ST \&

OBC) class at outskirt of city in the slums.

Water, santisation and health facilites are like denied to outskirt city population, all togethre they all have to depend on cities central palce where all the basic facilites are developed niceliy.

Overall these all above mentioned evidences proves the extrim discrimination and exclusion of not only SC,ST,OBC but also religious minority gropus at micro level.

\section{Recommendations:-}

1. Some were Govt. need to follow rules and regulation \& Implement effectively for all without discrimination. Or proper implementation of NCRLM and Sachar Committee report for the upliftment of these particular group.

2. Special Camping need to conduct for both the category Students (Socially, Economically superior and Backward people on same basis) on the issue of students misconception about education faculty. It has certain relation with historical societal status and their intellectual capacity.

3. NGO's with the help of educational institution's the socio-educational activity like education counselling, employment counselling sessions for the students as well to parents of students need to introduce.

4. Teacher's, Society, and Media all must take the note and be aware about the reality of Indian society's social stratification system and present reality on the scientific basis for all. This kind of brain washing needs to do for all. Then all these kind of misleading thoughts which are occupied in Indian's mind from all categories; will automatically get erased.

5. Govt. must provide basic rights to all its citizens like water, sanitation and health facility to nearest place. 
6. SRA, MAHADA, CIDCO- can work out the IGAY and RGAY for urban excluded (SC, ST, OBC and minority) people.

7. Social work profession need to address this issue in their style of overall inclusion of human being in all the sector of life and exclusion of irrelevant evidences which are affecting on human society.

8. Social work stream of education need to Help NGO's, Educational Institute, and Govt. for effectively implement above mentioned all recommendations and play the role of watch dog for Student Youth.

9. Social work Profession only can develop the kind of instrument which is sovereign, thoughtful, and logical, reality and practical oriented where all this components benefit can be taken care of. Like resource mapping, minority religious wise micro planning for each indicator like education, employment, health etc.

\section{References:-}

1. http://en.wikipedia.org/wiki/Mumbai_City_district\#cite_note-districtcensus-0.

2. http://www.Dharavislums.

3. Alam, M. S. (2009). Is Relative Size of Minority Population Linked to Underdevelopment? Economic \& Political Weekly , 44 (48), 17-21.

4. Arnold, E. (Ed.). (1977). Minorities in History. London: Erward Arnold Publishers Ltd.

5. Bhuimali, A. (2008). Minorities in India. New Delhi: Serials publications .

6. C, M. R. Problems of Higher Education In India (A Case Study). Delhi-110035: Mittal Publications.

7. Carson, D. (Ed.). (1991). Education for Work - Background to policy and Curriculam. Philadelphia: Multilingual Matters Ltd.

8. Chandra, R. (2004). Minority Social \& Political conflict (Vol. 3). Delhi, India: Isha Books.

9. Chitnis, S. (1988). Educating the weaker Sections of Society . In A. Singh, \& G. D. Sharma (Eds.), Higher Education In India - The Social Context (pp. 153-170). Delhi, India: Konar Publishers Pvt Ltd.

10. Desai, A. R., \& Pillai, S. D. (Eds.). (1990). Slums and Urbanization. Bombay, Maharashtra, India: Popular Prakashan.

11. Directorate of Census operation. (2001). Census of India 2001. Analytical tabel of Greater Mumbai Muncipal Corporation. Mumbai: Govt. of Maharashtra.

12. Directorate of economics and statistics, Planning Department. (2015). Economic Survey of Maharashtra 201415. Mumbai: Government of Maharashtra.

13. Engineer, A. A. (1985). Indian Muslims: A Study of the minority problems in India. Delhi: Ajanta Publications.

14. Fried, C. (Ed.). (1983). Life Science Research Report 27, Minorities: Communities and Identity . New York: Spinger-verlag.

15. Garg, V. K. (2011). Minority Rights. alfa publications.

16. Government of Maharashtra. (1960). Greater Bombay Disrict Gazetteer. Maharahstra State Gazetteers (Vol. 27). Bombay: Gazetteer Department.

17. Internatonal Institute of Population Sciences (IIPS). (2008). Youth in India: Situation and Needs $2006-07$. Mumbai: IIPS.

18. Ministry of Minority Affairs Govt. of India. (2007). National Commission for Religious and Linguistic Minorities. New Delhi: Govt. of India.

19. Mundu, G. B., \& Bhagat, R. B. (2008, March). Slum Conditions in Mumbai with Referance to the Access of Civic Amenities. 5 (1).

20. Peer, M. (1994). Higher Education and Employment. Jaipr and New Delhi: Rawat Publications.

21. Powar, K. B. (2012). Expanding Domains in Indian Higher Education. New Delhi: Association of Indian Universities.

22. Rajiv Gandhi National Institute of Youth Development (RGNIYD). (2010). Youth Development Index. Tamilnadu: Rajiv Gandhi National Institute of Youth Development (RGNIYD).

23. Sharma, J. B., \& Sharma, S. P. (1999). Studies in Indian culture, religion \& society series-6: Parsis in India . Jaipur, Rajasthan, India: Sublime Publishers Private Limited.

24. Thorat, S., \& Sabharwal, N. S. (2010). Caste and Social Exclusion: Issues Related to Concept, Indicators and Measurement. In Caste and Social Exclusion: Issues Related to Concept, Indicators and Measurement. New Delhi and Unicef (India): Indian Institute of Dalit Studies and UNICEF. 